\title{
SMOS calibration and validation activities with airborne interferometric radiometer HUT-2D during spring 2010
}

Kainulainen, J.; Rautiainen, K.; Sievinen, P.; Seppänen, J.; Rouhe, E.; Hallikainen, M.; Dall'Amico, J.; Schlenz, F.; Loew, A.; Bircher, Simone

Total number of authors:

11

Published in:

International Geoscience and Remote Sensing Symposium proceedings

Link to article, DOI:

10.1109/IGARSS.2010.5654137

Publication date:

2010

Document Version

Publisher's PDF, also known as Version of record

Link back to DTU Orbit

Citation $(A P A)$ :

Kainulainen, J., Rautiainen, K., Sievinen, P., Seppänen, J., Rouhe, E., Hallikainen, M., Dall'Amico, J., Schlenz, F., Loew, A., Bircher, S., \& Montzka, C. (2010). SMOS calibration and validation activities with airborne interferometric radiometer HUT-2D during spring 2010. In International Geoscience and Remote Sensing Symposium proceedings (pp. 702-705). IEEE. https://doi.org/10.1109/IGARSS.2010.5654137

\section{General rights}

Copyright and moral rights for the publications made accessible in the public portal are retained by the authors and/or other copyright owners and it is a condition of accessing publications that users recognise and abide by the legal requirements associated with these rights.

- Users may download and print one copy of any publication from the public portal for the purpose of private study or research.

- You may not further distribute the material or use it for any profit-making activity or commercial gain

- You may freely distribute the URL identifying the publication in the public portal 


\title{
SMOS CALIBRATION AND VALIDATION ACTIVITIES WITH AIRBORNE INTERFEROMETRIC RADIOMETER HUT-2D DURING SPRING 2010
}

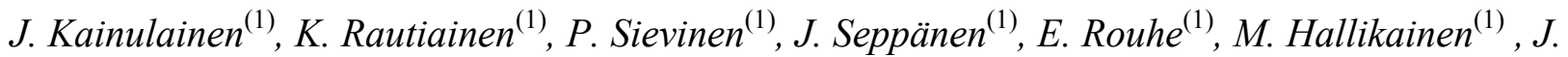

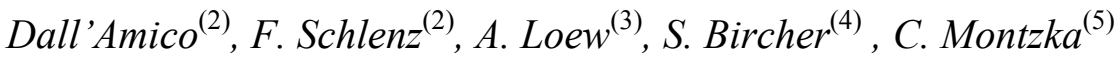 \\ (1) Aalto University, Department of Radio Science and Engineering, Espoo, Finland \\ ${ }^{(2)}$ University of Munich, Department of Geography, Munich, Germany \\ ${ }^{(3)}$ Max-Planck-Institute for Meteorology, Land in the Earth System, Hamburg, Germany \\ (4) Technical University of Denmark, DTU Space, Microwaves and Remote Sensing \\ ${ }^{(5)}$ Research Centre Juelich, Institute of Chemistry and Dynamics of the Geosphere, Agrosphere Institute \\ (ICG 4), Juelich, Germany
}

\begin{abstract}
In this paper we present calibration and validation activities of European Space Agency's SMOS mission, which utilize airborne interferomentric L-band radiometer system HUT2D of the Aalto University. During spring 2010 the instrument was used to measure three SMOS validation target areas, one in Denmark and two in Germany. We present these areas shortly, and describe the airborne activities. We show some exemplary measurements of the radiometer system and demonstrate the studies using the data.
\end{abstract}

Index Terms - radiometry, SMOS, soil moisture, interferometry

\section{INTRODUCTION}

The goal of the ESA SMOS (Soil Moisture and Ocean Salinity) mission is to provide accurate global soil moisture and ocean salinity data on a regular basis. The satellite was successfully launched in November 2009 and its only instrument is the MIRAS (Microwave Imaging Radiometer by Aperture Synthesis) sensor. It operates at a frequency of $1.4 \mathrm{GHz}$ (L-band) and employs interferometry to produce two-dimensional brightness temperature images of the Earth with a spatial resolution of 30 to $50 \mathrm{~km}$. These images are transformed into soil moisture and ocean salinity maps using recently developed algorithms. [1]

In order to support the SMOS mission, an airborne 1.4 $\mathrm{GHz}$ interferometric radiometer HUT-2D has been developed, constructed and tested by the Aalto University.
The HUT-2D sensor is accommodated onboard the University's remote sensing aircraft. The main technical parameters of HUT-2D are similar to those of MIRAS; hence, HUT-2D can be used to produce multi-angular data sets needed for the development and validation of SMOS algorithms. [2]

Since 2006 HUT-2D radiometer has participated in various measurement campaigns to obtain L-band datasets mainly for soil moisture and ocean salinity retrieval studies. Data sets for soil moisture retrieval have been collected over test sites with various land-cover conditions ranging from bare and crop-covered agricultural fields to boreal forests and bogs. Data sets for sea salinity studies have been collected over the Baltic Sea and various test sites in the coastal area of southern Finland.

Campaign with the HUT-2D radiometer system was carried out in the frame of SMOS calibration and validation activities in the April - June 2010. This campaign consists of multiple measurements of several soil moisture test areas in Denmark and Central and Southern Germany, all recognized as main soil moisture calibration and validation sites for SMOS. In this paper we describe the main characteristics of the data sets acquired with the HUT-2D instrument over these test sites.

\section{HUT-2D INSTRUMENT}

The HUT-2D instrument is described in detail in [2]. In short, it employs 36 receivers in a two-dimensional Ushaped configuration over a $7 \mathrm{MHz}$ frequency band centered at $1.4135 \mathrm{GHz}$. It utilizes the same fundamentals of 

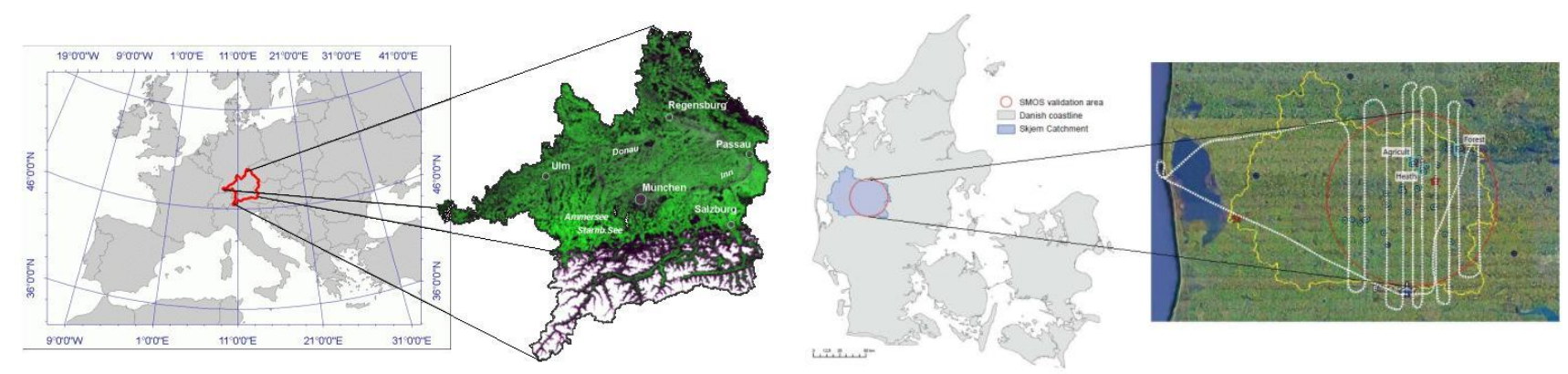

Figure 1. Left: Upper Danube Catchment (UDC) area in Southern Germany. Right: Validation area in Denmark. Flight track of one of the four measurement flights is indicated with white line.

interferometry and aperture synthesis as the SMOS payload does, and the main technical solutions, such as calibration techniques, are common for the two instruments.

HUT-2D is capable in measurements of two polarizations by switching between two orthogonally aligned antenna feeds in the receivers' front ends. Angular resolution provided by the aperture synthesis is approximately 7 degrees, and the size of two-dimensional brightness temperatures images, each produced in 250 milliseconds, is 7 times 7 pixels. From a typical flight altitude, e.g. 2000 meters, this makes the projection of the acquired image to cover a square with a side of 2300 meters. University's research aircraft Skyvan Short SC7 is capable in flight altitudes of 0-3000 meters above the sea level.

\section{SMOS VALIDATION AREAS}

The soil moisture calibration and validation activities presented in this paper consist of measurements of three river catchment areas described shortly in the following.

The Upper Danube Catchment (UDC), a temperate agricultural area situated mostly in Southern Germany, is one of two major SMOS validation test sites in Europe covering $77.000 \mathrm{~km} 2$. Its main part is situated in the alpine foreland with heterogeneous land cover and large natural gradients from the Alps northwards. The best soil moisture retrieval performance is expected in the smaller catchment of the river Vils, situated in the Northeast of the city of Munich. No open water bodies or large urban areas considerably affect the passive microwave signal in that area. The terrain as well as the soil is fairly homogeneous. Location of the test area is shown in Fig. 1, left.

The second test site in Germany, referred REC hereafter, encompasses the catchment basins of the rivers Rur and Erft, which are located in the Belgian-Dutch-German border region near the city of Aachen. The site can be separated into two main regions. The southern part covers the bedrock of the Eifel mountains, with a high long-term annual precipitation of $850-1300 \mathrm{~mm}$. This region consists of Devonian and Carboniferous sedimentary rocks with low permeability and small groundwater storage volumes, causing water runoff primarily linked to the fissure system. The northern region is characterized by soils evolved from loess, which accumulated on Tertiary and Quaternary depositions of the Rivers Rhine and Meuse. It has a relatively low annual precipitation of $650-850 \mathrm{~mm}$. In accordance with this hydrogeological and climatic division, the land use types are clearly distinguishable. Forest and grassland characterize the south, whereas in the north fertile agricultural land predominates. Multiple sensor systems have been installed in the Rur catchment aiming to create observation platforms for long-term statistical time series of system variables for the analysis and prognosis of global climate change consequences using integrated model systems, which will be used to derive efficient prevention, mitigation and adaptation strategies. The test area and some instrumentation is shown in Fig. 2.

The third test site is situated within the Skjern river catchment in Western Denmark (ca. $2500 \mathrm{~km} 2$ ) at short distance to the coast line (see Fig. 1, right). The climate in the area is temperate-maritime with annual precipitation of around $800-900 \mathrm{~mm}$. The largest fraction of the catchment consists of low-relief alluvial plains with sandy sediments, while the very eastern areas are covered by more loamy soils on calcareous tills of hilly appearance. In poorly drained basins, organic deposits are found. The predominant soil type is podsol. The major part of the land is under intensive

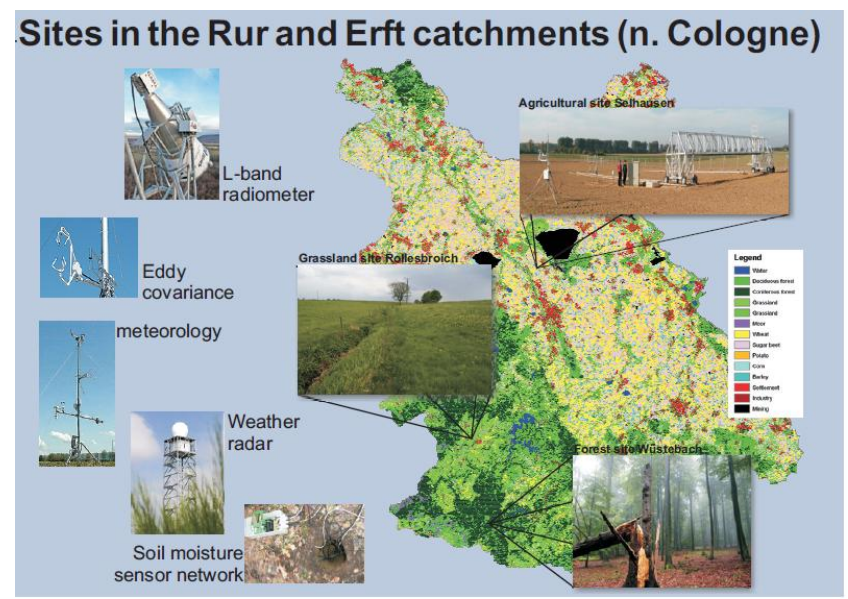

Figure 2. Rur and Erft Catchment area in Germany. 

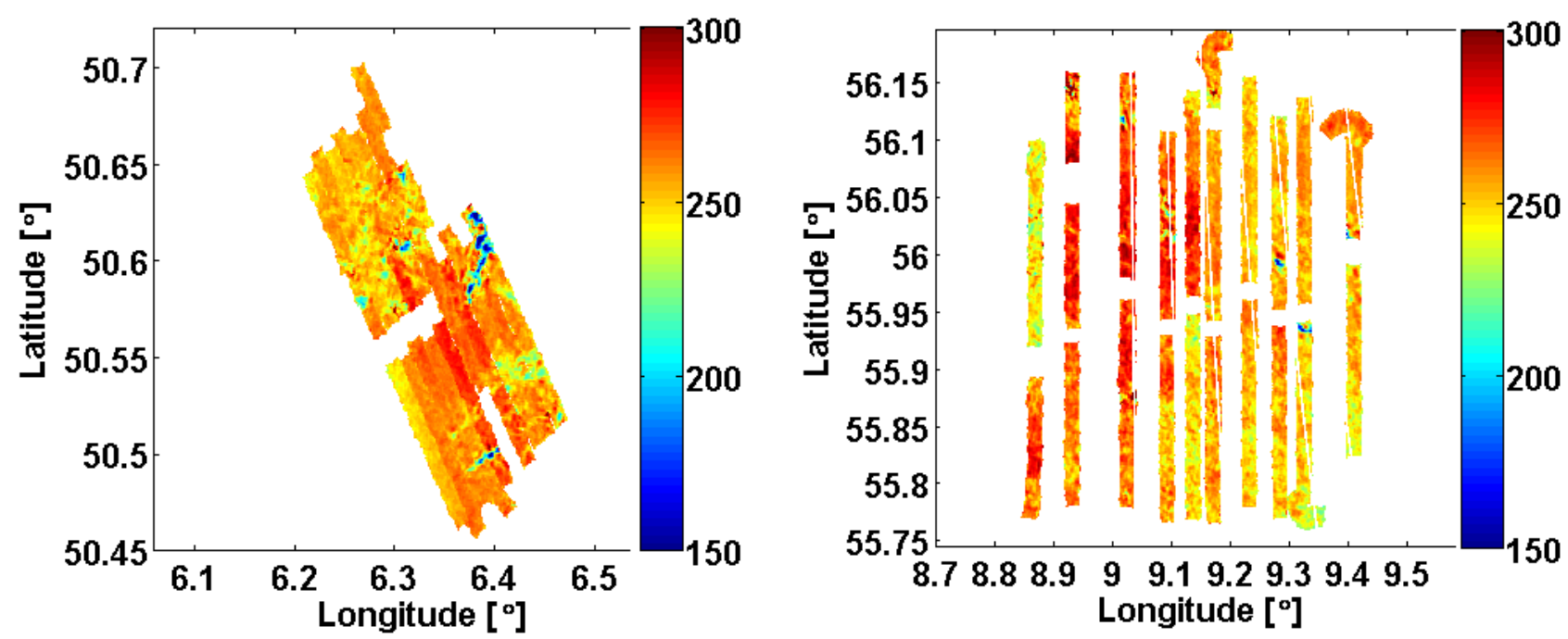

Figure 3. Brightness temperature mapped by the HUT-2D radiometer at the Upper Danube Catchment area in Southern Germany (left) and the test area in Denmark (right).

agricultural practice. Intermixed with farm land, patches of forest plantations (mostly spruce), grassland, heath, shrub and wetlands are encountered. The area is sparsely populated with scattered farms and single villages. Within the catchment an area corresponding to SMOS ground resolution ( $\sim 44 \mathrm{~km}$ diameter circle) is chosen to be validated by means of (1) measurements of a soil moisture network with 30 stations distributed throughout the area, and (2) the airborne campaign with concurrent snapshot ground measurements in three selected patches of differing land cover.

\section{OTHER INSTRUMENTATION OF THE AIRCRAFT}

In addition to the HUT-2D radiometer system a novel Lband polarimetric radiometer EMIRAD was installed into the research aircraft [3]. The radiometer system includes two fully polarized receivers. One of the EMIRAD's antennas one pointed to nadir and the other one is tilted 40 degrees off the nadir. Half power beam width of the antennas is approximately 36 degrees.

A nadir pointing infrared camera was installed in the nose cone of the aircraft to provide ground temperature information simultaneously with radiometric measurements.

Also, an onboard video camera was used to record the target areas for possible visual inspection.

\section{FLIGHT ACTIVITIES AT THE TEST AREAS}

The flight activities started in the end of April 2010 in Denmark, where four measurement flights were carried out. After Denmark, two flights were carried out at the REC test site and following that three at the UDC test site. After these measurement flights a two week break was scheduled for the campaign so that the soil moisture circumstances at the test areas could possibly change. After the break, two measurement flights were conducted at the UDC site and three at the REC site. The flight schedule is summarized in Table I.

At all the test sites, flights were scheduled to be simultaneous with SMOS ascending orbit overpasses. So, the flights were carried out in the mornings, around 6 o'clock the local times. Duration of each measurement flight was approximately 3 hours, which is limited by the aircraft's endurance.

Over the test areas, flight altitudes close to 3000 meters above sea level were used. Exception to this was the overpasses of the tower based radiometer systems at the REC and UDC sites. Over them the flight altitude was in the order of 1000 meter and less in order to enhance the spatial resolution of the instruments.

TABLE I

FLIGHT ACTIVITIES AT THE VALIDATION SITES

\begin{tabular}{ccc}
\hline \hline Date & Site & Notes \\
\hline 29.4. & Denmark & Nominal operations \\
2.5. & Denmark & Nominal operations \\
4.5. & Denmark & Nominal operations \\
9.5. & Denmark & Nominal operations \\
11.5. & REC & Interrupted by weather \\
14.5. & REC & Nominal operations \\
16.5. & UDC & Nominal operations \\
22.5. & UDC & Nominal operations \\
25.5. & UDC & Nominal operations \\
\hline & TWO WEEKS BREAK \\
\hline 12.6. & UDC & No HUT-2D measurements \\
17.6. & UDC & Nominal operations \\
22.6. & REC & Nominal operations \\
24.6. & REC & Nominal operations \\
27.6. & REC & Nominal operations \\
\hline
\end{tabular}




\section{REFERENCES}
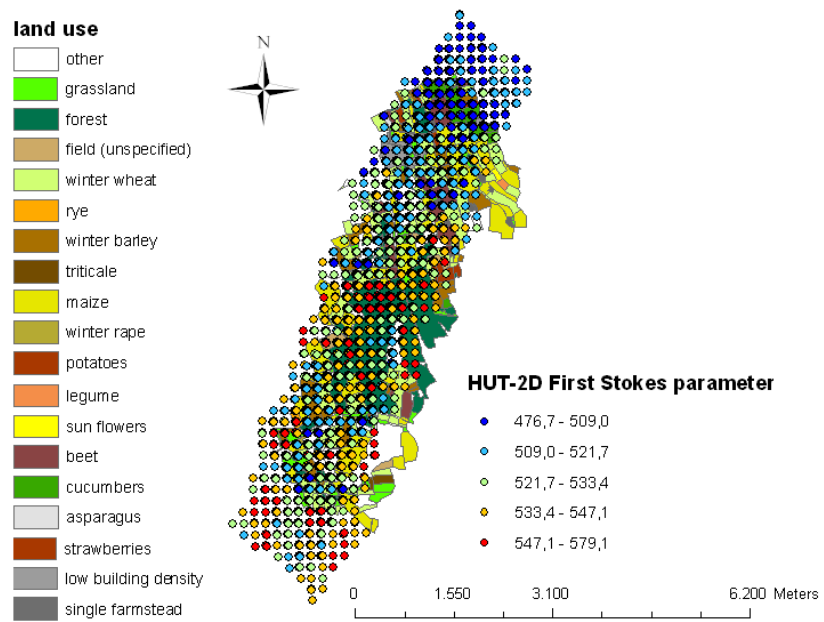

Figure 4. First Stokes parameter derived from the HUT-2D measurements over a particular test leg at the UDC test site. Land classification map is used in the soil moisture retrieval analysis.

\section{EARLY RESULTS}

The radiometric data from the campaigns is partially released at the moment and will be completely available in July 2010.

Ongoing activities utilizing HUT-2D data aim at validation of the simultaneously acquired SMOS measurements over the areas, as presented e.g. in studies [4] to [7]. Figure 4 shows the first comparison of the recent data with land classification. The studied parameter is the first Stokes parameter, i.e. the sum of the $\mathrm{H}$ and V-polarized emission component. The correlation of the Stokes parameter with heavily vegetated areas is obvious.

Some activities are established to study the synergy of having measurements from two, fundamentally very different, radiometer system simultaneously [5]. Similar study was already utilized e.g. in improving of the calibration of the HUT-2D system using the data from the SMOS Rehearsal campaign in spring 2008.

Data from the two radiometer systems are also used to study the existence and influence of RFI occurrences on the protected band they operate [8].

\section{ACKNOWLEDGMENTS}

Authors acknowledge Dr C. Bouzinac, the manager of the SMOS mission calibration and validation activities from the European Space Agency.
[1] K. D. McMullan, M. A. Brown, M. Martin-Neira, W. Rits, S. Ekholm, J. Marti and J. Lemanczyk, "SMOS: The payload," IEEE Trans. Geosci. Remote Sens., vol 46, pp. 594-605, Mar 2008.

[2] K. Rautiainen, J. Kainulainen, T. Auer, J. Pihlflyckt, J. Kettunen, M. Hallikainen, Helsinki University of Technology Lband Airborne Synthetic Aperture Radiometer. IEEE Trans. Geosci. Remote Sensing, vol. 46, pp. 717 - 726, 2008.

[3] R. Rotbøll, S.S. Søbjaerg, N. Skou, "A Novel L-band Polarimetric Radiometer Featuring Subharmonic Sampling", Radio Science, 38, 11-1 - 11-7, 2003.

[4] J. T. Dall'Amico, A. Loew, F. Schlenz, W. Mauser, "SMOS rehearsal campaign 2008: radiometer data analysis and soil moisture retrieval using the LPRM," Earth Observation and Water Cycle Conference, Frascati, Rome, 18-20 November 2009. ESA Special Publication SP-674.

[5] A. Loew, J. T. Dall'Amico, F. Schlenz, W. Mauser, "SMOS validation in the Upper Danube Catchment (UDC): A status report eight months after launch," ESA Living Planet Symposium 2010, Bergen, Norway, 28 June - 2 July 2010.

[6] C. Montzka, H. Bogena, J. Vanderborght, "SMOS Validation at the Rur and Erft catchments, Germany," ESA Living Planet Symposium, Bergen, Norway, 28 June - 2 July 2010.

[7] S. Bircher, J. Balling, N. Skou, "SMOS validation activities at different scales in the Skjern river catchment, Western DK," Presented in ESA Living Planet Symposium, Bergen, Norway, 28 June - 2 July 2010.

[8] M. Hallikainen, K. Rautiainen, J. Kainulainen, J. Seppänen, A. Hakkarainen, "Investigation of radio frequency interference at Lband using airborne radiometer data," Proc. $11^{\text {th }}$ Specialist Meeting on Radiometry and Remote Sensing Applications 2010, MicroRad'10, Washington D.C., 01 - 04 March 2010. 